\title{
Importance of the Structure of Vancomycin Binding Pocket in Designing Compounds Active Against Vancomycin-resistant Enterococci (VRE)
}

\author{
Yanxing Jia, Michèle Bois-Choussy, Adriano Malabarba, Cristina Brunati, Jieping Zhu
}

In memory of Professor Kenneth L. Rinehart

Received: May 31, 2006 / Accepted: September 12, 2006

(C) Japan Antibiotics Research Association

\begin{abstract}
Membered meta, para-cyclophanes mimicking the vancomycin binding pocket (D-O-E ring) are designed and synthesized. The structural features of these biaryl ether containing macrocycles are: a) the deletion of the carboxyl group of vancomycin's central amino acid (amino acid D); b) the elongation of the $N$-terminal; c) the presence of lipidated aminoglucose at the D-ring. Cycloetherification by way of an intramolecular nucleophilic aromatic substitution reaction $\left(\mathrm{S}_{\mathrm{N}} \mathrm{Ar}\right)$ is used as a key step for the construction of the macrocycle. Minimum inhibitory concentrations for all of the derivatives are measured using a standard microdilution assay. Compounds $\mathbf{2 a} \sim \mathbf{2 c}$ and $\mathbf{3 a} \sim \mathbf{3} \mathbf{c}$ displayed weak activities against resistant strain Enterococcus faecalis L560 and were inactive against Enterococcus faecium resistant strain L2215.
\end{abstract}

Keywords antibiotic, glycopeptide, intramolecular nucleophilic aromatic substitution, macrocycle, vancomycin, vancomycin-resistant enterococci (VRE)

\section{Introduction}

For over a quarter of century, vancomycin (Fig. 1) was one of the few antibiotics of the last resort for the treatment of infections due to methicillin-resistant Staphylococcus aureus and other Gram-positive organisms in patients

J. Zhu (Corresponding author), Y. Jia, M. Bois-Choussy: Institut de Chimie des Substances Naturelles, CNRS, 91198 Gif-surYvette Cedex, France, E-mail: zhu@icsn.cnrs-gif.fr allergic to $\beta$-lactam antibiotics [1]. Unfortunately, resistance to drugs of the vancomycin family has been recognized in the late 1980s and the frequency of resistance has increased significantly over the past decades, reaching $30 \%$ among hospitalized patients in 2002 in the USA. Since vancomycin-resistant enterococci (VRE) also carry resistance to virtually all other known antibiotics, it represents a serious threat to public health $[2,3]$.

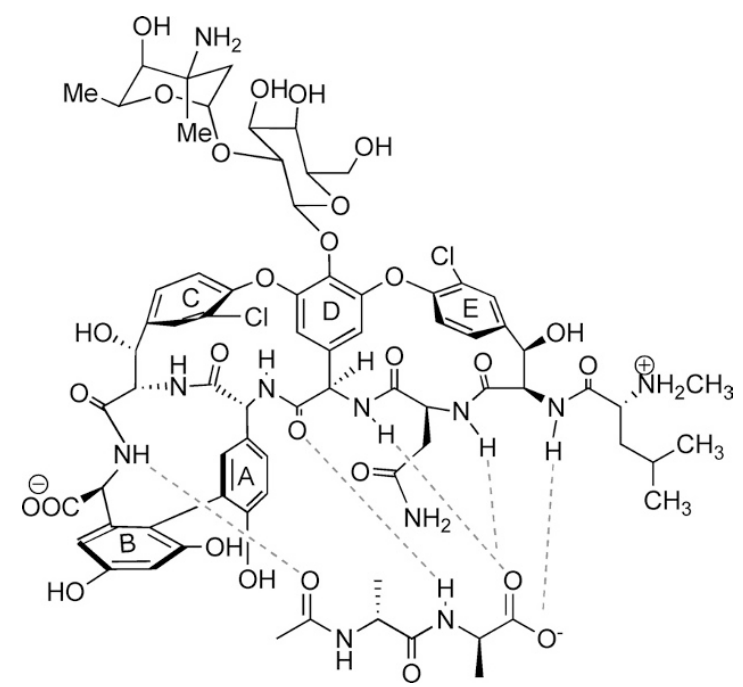

Fig. 1 Hydrogen bonding network of the vancomycin (1) and N-Ac-D-Ala-D-Ala complex.
A. Malabarba, C. Brunati: Vicuron Pharmaceuticals, Italy Research Center, via R. Lepetit, 34, I-21040 Gerenzano (VA), Italy 
<smiles>[R6]c1cc(CNC(=O)[C@H](Cc2ccccc2)NC(=O)[C@H](Cc2ccc(Oc3cc(OC)c(OC)c([N+](=O)[O-])c3)c([N+](=O)[O-])c2)NC(=O)[C@H](CC(C)C)NC(=O)CN)cc([N+](=O)[O-])c1</smiles><smiles>[R6]Oc1cc(CNC(=O)[C@H](Cc2ccccc2)NC(=O)[C@H](Cc2ccc(Oc3cc([O-])c(OC)c([N+](=O)[O-])c3)c([N+](=O)[O-])c2)NC(=O)[C@H](CC(C)C)NC(=O)CN)cc([N+](=O)[O-])c1</smiles>

a R $=\mathrm{H} ; \mathrm{bR}=\mathrm{COCH}_{2} \mathrm{NH}_{2}$;

c R $=2$ - $N$-lauroyl-2-amino-2-deoxy-D-glucopyranosyl

Fig. 2 Modified D-O-E ring of vancomycin.

Vancomycin acts by binding to the terminal D-alanylD-alanine (D-Ala-D-Ala) of the peptidoglycan precursors, thus blocking the final stages of the peptidoglycan synthesis. Bacteria become resistant to vancomycin by reprogramming the peptidoglycan termini from D-AlaD-Ala dipeptide to D-Ala-D-Lac (D-alanyl-D-lactate) depsipeptide that binds only weakly to the drug. In fact, in vitro binding studies have shown that the affinity of vancomycin for $N$-Ac-D-Ala-D-Lac is about 1000 times less than its affinity for $\mathrm{N}$-Ac-D-Ala-D-Ala, due to one missing hydrogen bond and the ground state repulsion between the two oxygen lone-pairs in the former complex. The reduced binding affinity translated into about 1000 -fold reduced sensitivity of vancomycin-resistant bacteria to this drug (Fig. 1) [4].

Extensive structure-activity relationship (SAR) studies on vancomycin and teicoplanin type glycopeptide performed by both academic and industrial researchers indicated that the incorporation of a hydrophobic chain into the natural product is highly beneficial for activities against VRE [5, 6]. Indeed both oritavancin (LY333328) [7] and dalbavancin [8], that entered into late-stage clinical trials, contain a hydrophobic group. Two theories have been proposed to account for oritavancin's bioactivity against VRE [1 4]. Williams hypothesized that the presence of a lipid chain in the disaccharide part of vancomycin enhanced avidity for D-Ala-D-Lac by facilitating membrane anchoring and/or by promoting dimerization [9]. On the other hand, Kahne has recently advanced that oritavancin acts against VRE by direct interaction with the transglycosylase without substrate binding $[10,11]$ and<smiles>CCCOc1cc(CN)cc(OCC)c1OC</smiles><smiles>CC(C)NC(Cc1ccc(F)c([N+](=O)[O-])c1)C(=O)NC(Cc1ccccc1)C(=O)O</smiles>

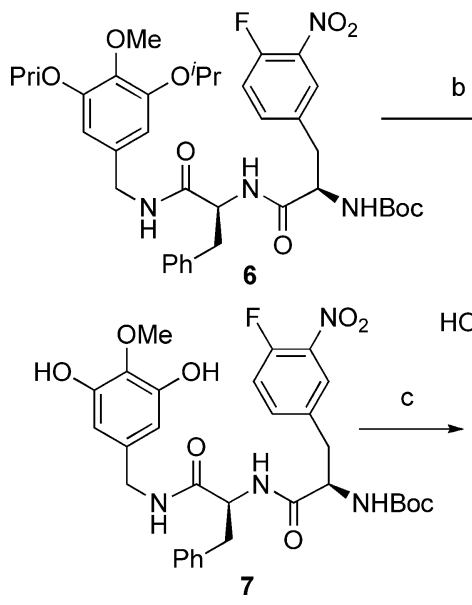

\section{Scheme 1}

Reagents and conditions: (a) HATU, DIPEA, DMF, $25^{\circ} \mathrm{C}, 12$ hours, $89 \%$; (b) i. $\mathrm{BCl}_{3}, \mathrm{CH}_{2} \mathrm{Cl}_{2}, 0^{\circ} \mathrm{C}$, 1 hour; then $\mathrm{MeOH}$; ii. $\mathrm{Boc}_{2} \mathrm{O}$, $\mathrm{NaHCO}_{3}$, dioxane/ $\mathrm{H}_{2} \mathrm{O}(2: 1), 25^{\circ} \mathrm{C}, 12$ hours, $73 \%$ (2 steps); (c) $\mathrm{CsF}, \mathrm{DMSO}, 25^{\circ} \mathrm{C}, 16$ hours, $65 \%$. HATU $=0$-(7-azabenzotriazol-1yl)- $N, N, N^{\prime}, N^{\prime}$-tetramethyluronium hexafluorophosphate, DIPEA= diisopropylethylamine.

evidences supportive to this view have been accumulated. We have been working on the design and synthesis of modified D-O-E ring of vancomycin and found that both the structure of the 16-membered macrocycle including the absolute configuration of the exo-cyclic stereocenter and the presence of a hydrophobic substituant (or a lipidated aminosugar) are important for the observed anti-VRE activities of our synthetic compounds [12 14]. As a continuation of this research project, we report herein the synthesis and biological activity evaluation of compound series 2, 3. The characteristic structural feature of these compounds are as follows: a) the deletion of the carboxyl group of vancomycin's central amino acid (amino acid D); b) the elongation of the $\mathrm{N}$-terminal; c) the presence of lipidated aminoglucose at the D-ring.

\section{Results and Discussion}

\section{Synthesis of Macrocycles 2 and 3}

Synthesis of the 16-membered meta, para-cyclophane 8 was accomplished as shown in Scheme 1. Coupling of 3,5- 
diisopropyloxy-4-methoxybenzylamine (4) with $N$-Boc-D(4-fluoro-3-nitro)phenylalanyl-L-phenylalanine (5) [14] afforded dipeptide $\mathbf{6}$ in $89 \%$ yield. Treatment of $\mathbf{6}$ with $\mathrm{BCl}_{3}$ led to the simultaneous deprotection of the isopropyl ether and the $N$-Boc function. Re-introduction of the Boc group furnished phenol 7 in $73 \%$ overall yield. The key intramolecular $\mathrm{S}_{\mathrm{N}} \mathrm{Ar}$-based cycloetherification of 7 was performed in DMSO (concentration of substrate: $0.01 \mathrm{M}$ ) in the presence of $\mathrm{CsF}$ at room temperature $[15,16]$. Two separable atropisomers 8 and $\mathbf{9}$ were isolated in $65 \%$ overall yield (ratio $\mathbf{8} / \mathbf{9}=3 / 2$ ). The absolute configuration of the planar chirality of $\mathbf{8}$ and $\mathbf{9}$ was deduced from detailed NOE studies. Thus, the NOE correlation between protons $\mathrm{H}^{a} / \mathrm{H}^{c}$ was observed in the NOESY spectrum of 8 , indicative of the $P$-configuration of this atropstereoisomer. On the other hand, a $\mathrm{H}^{b} / \mathrm{H}^{c}$ correlation, a characteristic of the $M$-atropstereoisomer, was observed for compound 9 [17].

Conversion of $\mathbf{8}$ to $\mathbf{2 c}$ was shown in Scheme 2. Removal of $N$-Boc function under mild acidic conditions afforded the free amine $\mathbf{1 0}$ that was coupled directly with $\mathrm{D}-\mathrm{N}$-Boc Leu (11) to furnish, after saponification, the tripeptide $\mathbf{1 2}$ in $63 \%$ yield. The $N$-deprotection followed by coupling with 2 equivalents of $\mathrm{N}$-Boc glycine provided compound $\mathbf{1 3}$ in $83 \%$ yield. Saponification of ester $\left(\mathrm{LiOH}, \mathrm{THF} / \mathrm{H}_{2} \mathrm{O}=3 / 1\right)$ afforded then the free phenol $\mathbf{1 4}$ in $98 \%$ yield. KoenigsKnorr reaction [18] of 14 with freshly prepared 3,4,6-tri-Oacetyl-2- $N$-lauroyl-2-amino-2-deoxy-D-glucopyranosyl bromide (15) under phase transfer conditions (10\% aqueous $\mathrm{Na}_{2} \mathrm{CO}_{3}, n \mathrm{Bu}_{4} \mathrm{NHSO}_{4}, \mathrm{CH}_{2} \mathrm{Cl}_{2}, \mathrm{rt}$ ) [19] afforded the desired $\beta$-glucoside 16 as the only isolable stereoisomer in $76 \%$ yield. Hydrolysis of acetate followed $\mathrm{N}$-deprotection afforded compound $\mathbf{2 c}$ in $80 \%$ yield. Compounds $\mathbf{2 a}$ and 2b (Fig. 2) were obtained by cleavage of $N$-protecting groups from 14 and 13 , respectively, under mild acidic conditions (TFA, $\mathrm{CH}_{2} \mathrm{Cl}_{2}$, rt).

Since we have previously demonstrated that the stereochemistry of the exo-cyclic chiral center has great influence of macrocycle's bioactivities [12 14], compounds 3a $\sim \mathbf{3 c}$ (Fig. 2) have also been synthesized following the same synthetic scheme using L-leucine as coupling partner.

\section{Antibiotic Activity Evaluation}

Minimum inhibitory concentrations for these compounds as well as reference compounds (vancomycin, teicoplanin) are measured using a standard microdilution assay. The selected results are summarized in Table 1. For the sake of comparison, the anti VRE activities of previously synthesized compounds $\mathbf{1 7}$ and $\mathbf{1 8}$ (Fig. 3) were also enlisted in the same table [14]. As it is seen, compounds $\mathbf{2 a} \sim \mathbf{2} \mathbf{c}$ and $\mathbf{3 a} \sim \mathbf{3} \mathbf{c}$ displayed poor activities against resistant

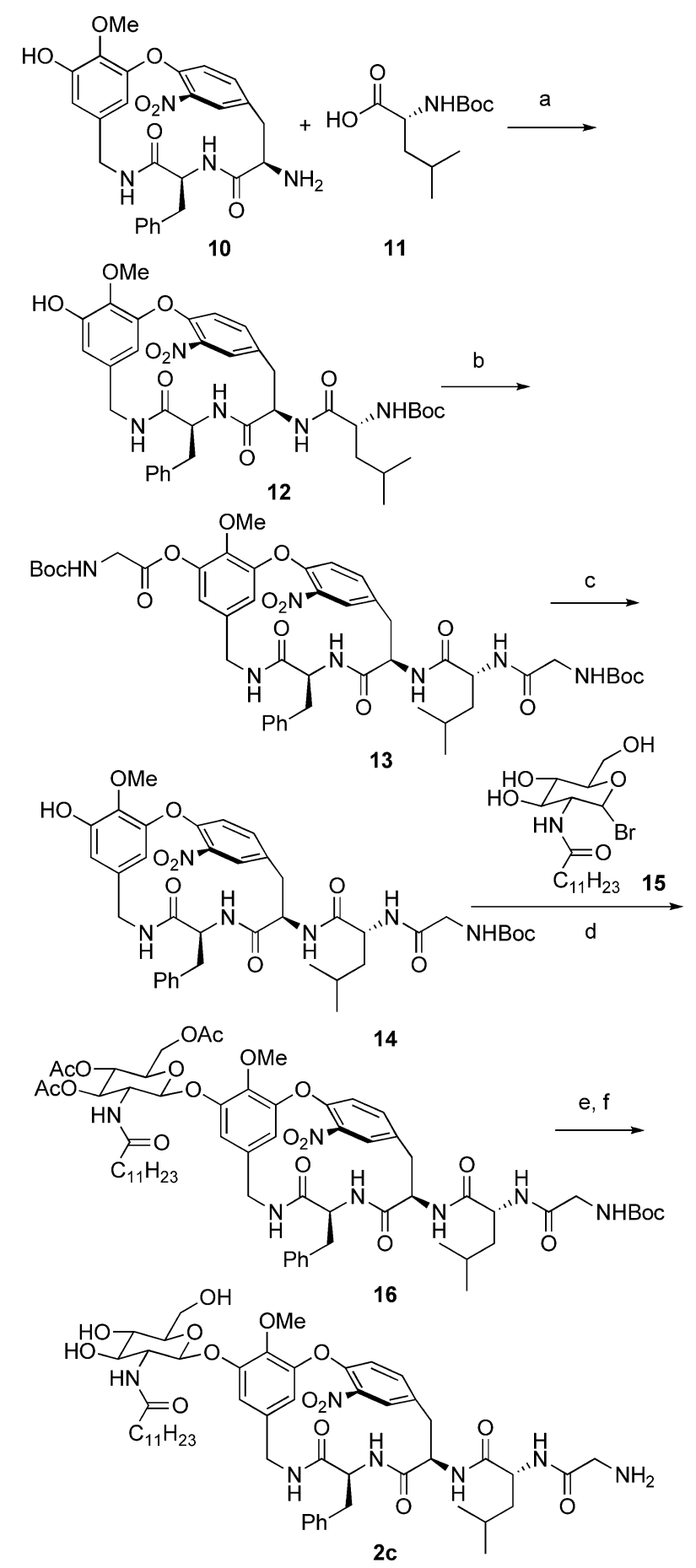

Scheme 2

Reagents and conditions: (a) i. HATU, DIPEA, DMF, $25^{\circ} \mathrm{C}, 12$ hours; ii. $\mathrm{LiOH}, \mathrm{THF} / \mathrm{H}_{2} \mathrm{O}(3: 1), 0^{\circ} \mathrm{C}, 1$ hour, $63 \%$ (2 steps); (b) i. TFA, $\mathrm{CH}_{2} \mathrm{Cl}_{2}, 0^{\circ} \mathrm{C}, 1$ hour; ii. HATU, DIPEA, DMF, $25^{\circ} \mathrm{C}, 12$ hours, 83\%; (c) $\mathrm{LiOH}, \mathrm{THF} / \mathrm{H}_{2} \mathrm{O}$ (3:1), $0^{\circ} \mathrm{C}, 1$ hour, 98\%; (d) $\mathbf{1 5}$, $(n \mathrm{Bu})_{4} \mathrm{NHSO}_{4}, 10 \%$ aqueous $\mathrm{Na}_{2} \mathrm{CO}_{3} / \mathrm{CH}_{2} \mathrm{Cl}_{2}(1: 1), 25^{\circ} \mathrm{C}, 4$ hours, $76 \%$; e) $\mathrm{LiOH}, \mathrm{THF} / \mathrm{H}_{2} \mathrm{O}(3: 1), 0^{\circ} \mathrm{C}, 1$ hour; f) TFA, $\mathrm{CH}_{2} \mathrm{Cl}_{2}, 0^{\circ} \mathrm{C}$, 1 hour, 80\% (2 steps). 
Table 1 MICs $(\mu \mathrm{g} / \mathrm{ml})$ of selected macrocycles and reference compounds. ${ }^{a}$

\begin{tabular}{|c|c|c|c|c|c|}
\hline \multirow{2}{*}{ Entry } & \multirow{2}{*}{ Cmpd. } & \multicolumn{2}{|c|}{ E. faecium } & \multicolumn{2}{|c|}{ E. faecalis } \\
\hline & & sensitive $^{b}$ & resistant $^{c}$ & sensitive $^{d}$ & resistant ${ }^{e}$ \\
\hline 1 & $2 a$ & $>128$ & $>128$ & 128 & 128 \\
\hline 2 & $2 b$ & $>128$ & $>128$ & $>128$ & 128 \\
\hline 3 & $2 c$ & $>128$ & $>128$ & $>128$ & 128 \\
\hline 4 & $3 a$ & $>128$ & $>128$ & $>128$ & 128 \\
\hline 5 & $3 b$ & $>128$ & $>128$ & $>128$ & 128 \\
\hline 6 & $3 c$ & $>128$ & $>128$ & $>128$ & 128 \\
\hline 7 & 17 & 64 & 32 & 8 & 8 \\
\hline 8 & 18 & 128 & 32 & 8 & 8 \\
\hline 9 & Vancomycin & 2 & $>128$ & 1 & $>128$ \\
\hline 10 & Teicoplanin & 0.5 & $>128$ & 0.125 & 64 \\
\hline
\end{tabular}

${ }^{a} \mathrm{MICs}=$ Minimum Inhibitory Concentrations; ${ }^{b}$ Bacterial strain L568 (isogenic of L569); ${ }^{c}$ Bacterial strain L2215 clinical isolate Van-A; ${ }^{d}$ Bacterial strain L559 (isogenic of L560); ${ }^{e}$ Bacterial strain L560.

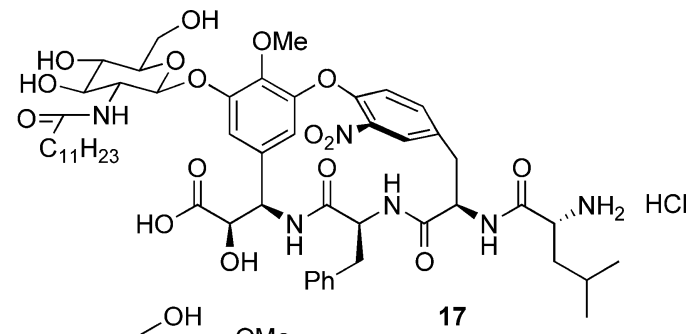

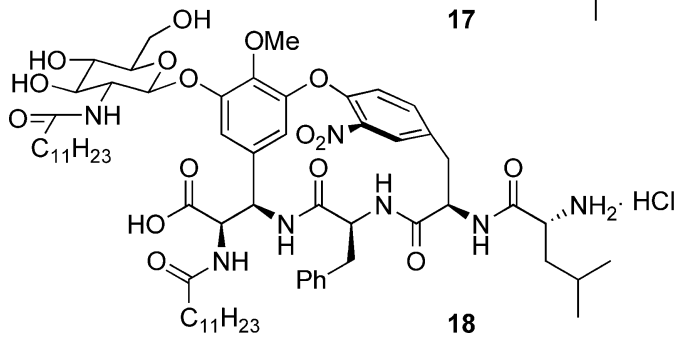

Fig. 3

strain Enterococcus faecalis L560 and were inactive against clinically more relevant $E$. faecium resistant strain L2215.

Compounds $\mathbf{2}$ and $\mathbf{3}$ were designed based on following reasoning: a) the deletion of the carboxyl group of the vancomycin's central amino acid D ( $c f$. Fig. 1) to avoid the unfavorable electrostatic interaction with the modified peptidoglycan terminal D-Ala-D-Lac $[20,21]$; b) the $N$ terminal was elongated in order to introduce an additional hydrogen-bonding with D-Ala-D-Lac [22]. In order to explore the possible conformational effect, hence the relative three-dimensional orientation of $\mathrm{NHs}$, compound 2 and $\mathbf{3}$ having D-Leucine (found in vancomycin), and D-leucine, respectively, were synthesized; the glycine was attached to leucine terminal in order to incorporate

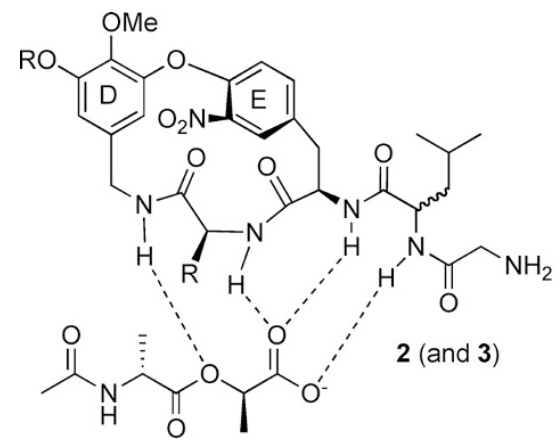

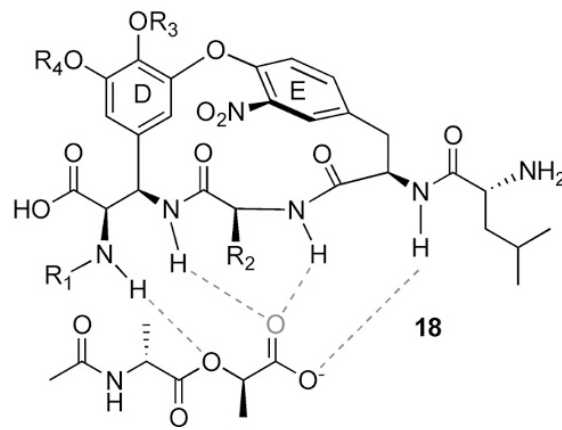

Fig. 4 Hypothetic complexes of 2(3)/D-Ala-D-Lac and 18/DAla-D-Lac.

potentially a fourth $\mathrm{NH}$ group that could interact with the carboxyl group of the D-Ala-D-Lac. Overall a hypothetical interaction between compound $\mathbf{2}$ (or $\mathbf{3}$ ) and $N$-Ac-D-Ala-DLac was depicted in Fig. 4; c) a lipidated aminoglucose was incorporated at the D-ring in order to explore the hydrophobic effect. For the sake of clearity, the hypothetic binding between 18 and $N$-Ac-D-Ala-D-Lac was also 
depicted in the Fig. 4.

In contrast to compounds $\mathbf{1 7}$ and $\mathbf{1 8}$ (Fig. 3) that displayed potent activities against VRE (entry 7,8), both $\mathbf{2}$ and 3 were relatively impotent against the same resistant strains. Since both $\mathbf{2 c}(\mathbf{3 c})$ and $\mathbf{1 7}(\mathbf{1 8})$ contained the same lipidated aminoglucose at the same position and they differed only in the structure of the central amino acid (segment D), the present results reinforced our previous conclusion regarding the importance of the structure of the macrocycle in searching for compounds active against VRE.

\section{Conclusion}

In summary, we have designed and synthesized molecules of a general structure (2 and $\mathbf{3}$ ) in which the carboxylic acid group of vancomycin's central amino acid D was deleted and the $N$-terminal was elongated. These compounds including $\mathbf{2 c}$ and $\mathbf{3 c}$ with a lipidated aminoglucose at the Dring displayed only weak activity against E. faecalis resistant strain and were inactive against clinically more relevant E. faecium resistant strain. We have previously demonstrated, by detailed SAR studies, the importance of the hydrophobic chain in the active compounds, we shown here that the structure of macrocycle is equally important in searching for compounds active against VRE.

\section{Experimental}

\section{General Methods}

Melting points were recorded using Reichert melting point apparatus. Infrared spectra were recorded on a Nicolet 205 FT-IR spectrometer. NMR spectra were performed on a Bruker AC-300 (300 MHz) spectrometer. Mass spectra were obtained from an AEI MS-9 using electron spray (ES). Optical rotation was measured on a Jasco P-100 polarimetre.

\section{Compound 4}

To a solution of 3,5-diisopropyloxy-4-methoxy benzyl alcohol (1.21 g, $4.76 \mathrm{mmol})$ [17] in toluene $/ \mathrm{CH}_{2} \mathrm{Cl}_{2}$ (3:1, $24 \mathrm{ml})$ was added $\mathrm{PBr}_{3}(0.48 \mathrm{ml}, 4.76 \mathrm{mmol})$ at $0^{\circ} \mathrm{C}$, and the mixture was stirred at r.t. for overnight. The reaction was quenched with water, and extracted with ether. The ether layer was washed with sat. $\mathrm{NaHCO}_{3}$ and brine successively, dried over $\mathrm{Na}_{2} \mathrm{SO}_{4}$. The solvent was concentrated and the residue was purified by column chromatograph $\left(\mathrm{SiO}_{2}\right.$, eluant: heptane/EtOAc $=15 / 1)$ to give the bromide $(1.38 \mathrm{~g}$, 92\%). IR $\left(\mathrm{CHCl}_{3}\right)$ 3426, 3025, 2929, 2856, 1746, 1685,
$1584,1521,1492,1434,1369,1345,1234,1165,1112$, $1034,849 \mathrm{~cm}^{-1} ;{ }^{1} \mathrm{H}$ NMR $\left(300 \mathrm{MHz}, \mathrm{CDCl}_{3}\right) \delta 6.59(\mathrm{~s}$, $2 \mathrm{H}$ ), 4.52 (hept, $J=6.2 \mathrm{~Hz}, 2 \mathrm{H}), 4.42$ (s, $2 \mathrm{H}), 3.81$ (s, 3H), $1.35(\mathrm{~d}, J=6.2 \mathrm{~Hz}, 12 \mathrm{H}) ;{ }^{13} \mathrm{C}$ NMR $\left(75 \mathrm{MHz}, \mathrm{CDCl}_{3}\right) \delta$ 152.0, 141.5, 132.8, 110.4, 71.9, 60.6, 34.5, 22.4; MS (ESI): $m / z 237(\mathrm{M}-\mathrm{Br})^{+}$.

To a solution of the above bromide in anhydrous DMSO $(5.0 \mathrm{ml})$ was added $\mathrm{NaN}_{3}(464 \mathrm{mg}, 7.14 \mathrm{mmol})$. After stirred at $30^{\circ} \mathrm{C}$ for 24 hours under Ar, the reaction was cooled to room temperature and diluted with $\mathrm{H}_{2} \mathrm{O}$ and extracted with EtOAc. The organic phase was washed with $\mathrm{H}_{2} \mathrm{O}$ and brine, dried over anhydrous $\mathrm{Na}_{2} \mathrm{SO}_{4}$. The solvent was removed and the residue was purified by flash chromatography $\left(\mathrm{SiO}_{2}\right.$, eluant: heptane/EtOAc $\left.=35: 1\right)$ to afford azide $(1.08 \mathrm{~g}, 88 \%)$. IR $\left(\mathrm{CHCl}_{3}\right) 3526,3025,3018$, 2980, 2937, 2101, 1590, 1499, 1435, 1385, 1374, 1363, 1333, 1321, 1209, 1137, 1115, 1080, 1005, $905 \mathrm{~cm}^{-1} ;{ }^{1} \mathrm{H}$ NMR $\left(300 \mathrm{MHz}, \mathrm{CDCl}_{3}\right) \delta 6.51(\mathrm{~s}, 2 \mathrm{H}), 4.53$ (hept, $J=6.2 \mathrm{~Hz}, 2 \mathrm{H}), 4.22$ (s, 2H), 3.82 (s, 3H), 1.35 (d, $J=6.2 \mathrm{~Hz}, 12 \mathrm{H}) ;{ }^{13} \mathrm{C}$ NMR $\left(75 \mathrm{MHz}, \mathrm{CDCl}_{3}\right) \delta 152.2$, 141.4, 130.5, 109.7, 72.0, 60.6, 55.1, 22.4; HRMS (ESI): $m / z$ calcd for $\mathrm{C}_{14} \mathrm{H}_{21} \mathrm{~N}_{3} \mathrm{O}_{3} \mathrm{Na}(\mathrm{M}+\mathrm{Na})^{+} 302.1481$; found 302.1476 .

To a solution of azide $(300 \mathrm{mg}, 1.08 \mathrm{mmol})$ in THF (10 ml) was added $\mathrm{Ph}_{3} \mathrm{P}(423 \mathrm{mg}, 1.61 \mathrm{mmol})$ and $\mathrm{H}_{2} \mathrm{O}$ $(194 \mu 1,10.8 \mathrm{mmol})$ at room temperature. After being stirred for 20 hours at the same temperature, The solvent was removed under vacuum and the residue was purified by flash column chromatography $\left(\mathrm{SiO}_{2}\right.$, eluant: $\mathrm{CH}_{2} \mathrm{Cl}_{2} / \mathrm{MeOH}=60 / 1$ to $10 / 1$ ) to afford 3,5-diisopropyloxy4-methoxy benzyl amine $(4,235 \mathrm{mg}, 86 \%) .{ }^{1} \mathrm{H}$ NMR $\left(300 \mathrm{MHz}, \mathrm{CDCl}_{3}\right) \delta 6.50$ (s, 2H), 4.50 (hept, $J=6.2 \mathrm{~Hz}$, $2 \mathrm{H}), 3.77(\mathrm{~s}, 3 \mathrm{H}), 3.73(\mathrm{~s}, 2 \mathrm{H}), 1.82(\mathrm{~s}, 2 \mathrm{H}), 1.31(\mathrm{~d}$, $J=6.2 \mathrm{~Hz}, 12 \mathrm{H}) ;{ }^{13} \mathrm{C} \mathrm{NMR}\left(75 \mathrm{MHz}, \mathrm{CDCl}_{3}\right) \delta 152.0$, 140.2, 138.3, 108.5, 71.7, 60.5, 46.5, 22.3; MS (ESI): $\mathrm{m} / \mathrm{z}$ $507(2 \mathrm{M}+\mathrm{H})^{+} ; 237\left(\mathrm{M}+\mathrm{H}-\mathrm{NH}_{3}\right)^{+}$.

\section{Compound 6}

To a solution of amine $4(330 \mathrm{mg}, 1.30 \mathrm{mmol})$ and acid 5 [23] (500 mg, $1.05 \mathrm{mmol})$ in DMF $(15 \mathrm{ml})$ was added DIPEA $(368 \mu \mathrm{l}, 2.1 \mathrm{mmol})$ and HATU (599 mg, $1.58 \mathrm{mmol})$. The reaction mixture was stirred at room temperature for 12 hours before it was extracted with EtOAc. The organic phase was washed with 5\% aqueous $\mathrm{HCl}$, saturated $\mathrm{NaHCO}_{3}$, brine, dried over $\mathrm{Na}_{2} \mathrm{SO}_{4}$, and concentrated under vacuum. The residue was purified by flash column chromatography $\left(\mathrm{SiO}_{2}\right.$, eluant: $\left.\mathrm{CH}_{2} \mathrm{Cl}_{2} / \mathrm{MeOH}=80 / 1\right)$ to afford $6(663 \mathrm{mg}, 89 \%)$. $[\alpha]_{\mathrm{D}}^{23}+2.3\left(c 1.0, \mathrm{CHCl}_{3}\right) ; \mathrm{IR}\left(\mathrm{CHCl}_{3}\right) 3427,3029,2981$, $1669,1590,1498,1437,1352,1231,1211,1160,1115$, 1082, 1006, $906 \mathrm{~cm}^{-1} ;{ }^{1} \mathrm{H}$ NMR $\left(300 \mathrm{MHz}, \mathrm{CDCl}_{3}\right) \delta 7.77$ 
(d, $J=5.9 \mathrm{~Hz}, 1 \mathrm{H}), 7.27 \sim 7.06(\mathrm{~m}, 8 \mathrm{H}), 6.72(\mathrm{br} \mathrm{s}, 1 \mathrm{H})$, $6.38(\mathrm{~s}, 2 \mathrm{H}), 5.48(\mathrm{brs}, 1 \mathrm{H}), 4.66(\mathrm{q}, J=7.4 \mathrm{~Hz}, 1 \mathrm{H}), 4.46$ (hept, $J=6.2 \mathrm{~Hz}, 2 \mathrm{H}), 4.38(\mathrm{~m}, 1 \mathrm{H}), 4.22(\mathrm{~d}, J=4.4 \mathrm{~Hz}$, $2 \mathrm{H}), 3.76(\mathrm{~s}, 3 \mathrm{H}), 3.11 \sim 3.03(\mathrm{~m}, 3 \mathrm{H}), 2.85 \sim 2.78(\mathrm{~m}, 1 \mathrm{H})$, $1.34 \sim 1.29(\mathrm{~m}, 21 \mathrm{H}) ;{ }^{13} \mathrm{C}$ NMR $\left(75 \mathrm{MHz}, \mathrm{CDCl}_{3}\right) \delta 171.0$, $170.8,155.4,154.4(\mathrm{~d}, J=263 \mathrm{~Hz}), 151.9,140.5,136.6$, $136.5,134.1,133.5,132.9,129.3$ (2C), 128.6 (2C), 127.0, 126.8, 118.1 (d, $J=20 \mathrm{~Hz}), 109.2,109.0$ (2C), 80.2, 71.6 (2C), 60.4, 55.1, 54.7, 43.9, 43.7, 38.6, 28.2 (3C), 22.2 (4C); HRMS (ESI): $m / z$ calcd for $\mathrm{C}_{37} \mathrm{H}_{47} \mathrm{~N}_{4} \mathrm{O}_{9} \mathrm{FNa}$ $(\mathrm{M}+\mathrm{Na})^{+}$733.3225; found 733.3223 .

\section{Compound 7}

To a solution of 6 (790 mg, $1.11 \mathrm{mmol})$ in $\mathrm{CH}_{2} \mathrm{Cl}_{2}(22 \mathrm{ml})$ was added $\mathrm{BCl}_{3}\left(1 \mathrm{M}\right.$ in $\left.\mathrm{CH}_{2} \mathrm{Cl}_{2}, 22.2 \mathrm{ml}, 22.2 \mathrm{mmol}\right)$ at $0^{\circ} \mathrm{C}$. After being stirred for 1 hour at $0^{\circ} \mathrm{C}$, the reaction was quenched by slow addition of anhydrous $\mathrm{MeOH}$. The volatile was evaporated and the residue was dissolved in dioxane $/ \mathrm{H}_{2} \mathrm{O}(2: 1,45 \mathrm{ml})$, and then $\mathrm{NaHCO}_{3}(932 \mathrm{mg}$, $11.1 \mathrm{mmol})$ and $\mathrm{Boc}_{2} \mathrm{O}(271 \mathrm{mg}, 1.22 \mathrm{mmol})$ was added. After being stirred at room temperature for overnight, the mixture was diluted with $\mathrm{H}_{2} \mathrm{O}$ and acidified with $5 \% \mathrm{HCl}$ to $\mathrm{pH} 3 \sim 4$, and extracted with EtOAc. The combined organic layer was washed with $\mathrm{H}_{2} \mathrm{O}$, brine, dried over $\mathrm{Na}_{2} \mathrm{SO}_{4}$, and concentrated under vacuum. The residue was purified by flash column chromatography $\left(\mathrm{SiO}_{2}\right.$, eluant: $\left.\mathrm{CH}_{2} \mathrm{Cl}_{2} / \mathrm{MeOH}=50 / 1\right)$ to afford $7(510 \mathrm{mg}, 73 \%)$. Mp $122 \sim 124^{\circ} \mathrm{C} ;[\alpha]_{\mathrm{D}}^{23}+15.4\left(\right.$ c $\left.0.70, \mathrm{CHCl}_{3}\right)$; IR $\left(\mathrm{CHCl}_{3}\right)$ 3526, 3297, 3024, 1670, 1603, 1539, 1499, 1458, 1353, 1252, 1167, 1061, 996, $835 \mathrm{~cm}^{-1}$; ${ }^{1} \mathrm{H}$ NMR $(300 \mathrm{MHz}$, $\left.\mathrm{CDCl}_{3}\right) \delta 7.68(\mathrm{~m}, 1 \mathrm{H}), 7.65(\mathrm{~d}, J=9.4 \mathrm{~Hz}, 1 \mathrm{H}), 7.46(\mathrm{br} \mathrm{s}$, $1 \mathrm{H}), 7.27 \sim 7.03(\mathrm{~m}, 9 \mathrm{H}), 6.22(\mathrm{~s}, 2 \mathrm{H}), 5.51(\mathrm{~d}, J=7.9 \mathrm{~Hz}$, $1 \mathrm{H}), 4.91(\mathrm{q}, J=7.2 \mathrm{~Hz}, 1 \mathrm{H}), 4.44(\mathrm{~m}, 1 \mathrm{H}), 4.37(\mathrm{dd}$, $J=6.4,15.1 \mathrm{~Hz}, 1 \mathrm{H}), 3.98(\mathrm{dd}, J=4.1,15.1 \mathrm{~Hz}, 1 \mathrm{H}), 3.83$ (s, 3H), 3.14 2.93 (m, 3H), 2.43 (dd, $J=8.7,13.6 \mathrm{~Hz}, 1 \mathrm{H})$, $1.33(\mathrm{~s}, 9 \mathrm{H}) ;{ }^{13} \mathrm{C}$ NMR $\left(75 \mathrm{MHz}, \mathrm{CDCl}_{3}\right) \delta 171.9,171.5$, 155.7, 154.4 (d, $J=265 \mathrm{~Hz}), 149.5$ (3C), 136.9 (d, $J=6.6 \mathrm{~Hz}), 136.4(\mathrm{~d}, J=7.7 \mathrm{~Hz}), 136.0,133.9,133.4,129.3$ (2C), 128.7 (2C), 127.2, 126.7, $118.3(\mathrm{~d}, J=21 \mathrm{~Hz}), 107.0$ (2C), 80.9, 67.1, 60.8, 54.7, 43.5, 38.7, 36.8, 28.1 (3C); HRMS (ESI): $m / z$ calcd for $\mathrm{C}_{31} \mathrm{H}_{35} \mathrm{~N}_{4} \mathrm{O}_{9} \mathrm{FNa}(\mathrm{M}+\mathrm{Na})^{+}$ 649.2286; found 649.2304.

\section{Compounds 8 and 9}

A solution of $7(475 \mathrm{mg}, 0.76 \mathrm{mmol})$ and anhydrous CsF $(238 \mathrm{~g}, 76 \mathrm{mmol})$ in dry DMSO $(76 \mathrm{ml})$ was stirred at room temperature for 16 hours. The reaction mixture was diluted with saturated aqueous $\mathrm{NH}_{4} \mathrm{Cl}$, acidified with $5 \% \mathrm{HCl}$ to $\mathrm{pH} 4$, and extracted with EtOAc. The combined organic layer was washed with $\mathrm{H}_{2} \mathrm{O}$, brine, dried over $\mathrm{Na}_{2} \mathrm{SO}_{4}$, and concentrated under vacuum. The residue was purified by flash column chromatography $\left(\mathrm{SiO}_{2}\right.$, eluant: $\mathrm{CH}_{2} \mathrm{Cl}_{2} / \mathrm{MeOH}=100 / 1$ to $\left.60 / 1\right)$ to afford $8(180 \mathrm{mg}, 39 \%)$ and 9 (120 mg, 27\%). For compound 8: $\mathrm{Mp} 163 \sim 165^{\circ} \mathrm{C}$; $[\alpha]_{\mathrm{D}}^{23}+107\left(c 0.90, \mathrm{CHCl}_{3}\right)$; IR $\left(\mathrm{CHCl}_{3}\right) 3525,3434,3020$, 2937, 1717, 1664, 1595, 1536, 1513, 1456, 1437, 1353, 1242, 1167, 1088, 1044, 994, $856 \mathrm{~cm}^{-1} ;{ }^{1} \mathrm{H}$ NMR $\left(300 \mathrm{MHz}, \mathrm{CDCl}_{3}\right) \delta 7.78(\mathrm{~d}, J=2.3 \mathrm{~Hz}, 1 \mathrm{H}), 7.35(\mathrm{dd}$, $J=2.3,8.7 \mathrm{~Hz}, 1 \mathrm{H}), 7.24 \sim 7.07(\mathrm{~m}, 6 \mathrm{H}), 6.87(\mathrm{~d}, J=8.7 \mathrm{~Hz}$, $1 \mathrm{H}), 6.77(\mathrm{~d}, J=8.7 \mathrm{~Hz}, 1 \mathrm{H}), 6.27(\mathrm{~d}, J=1.9 \mathrm{~Hz}, 1 \mathrm{H}), 5.53$ $(\mathrm{d}, J=7.2 \mathrm{~Hz}, 1 \mathrm{H}), 5.40(\mathrm{~d}, J=1.9 \mathrm{~Hz}, 1 \mathrm{H}), 5.23(\mathrm{~d}$, $J=7.5 \mathrm{~Hz}, 1 \mathrm{H}), 4.71(\mathrm{dd}, J=9.0,15.4 \mathrm{~Hz}, 1 \mathrm{H}), 4.66(\mathrm{~m}$, $1 \mathrm{H}), 4.26$ (ddd, $J=5.3,8.7,9.4 \mathrm{~Hz}, 1 \mathrm{H}), 3.95$ (s, 3H), 3.52 (dd, $J=4.9,13.6 \mathrm{~Hz}, 1 \mathrm{H}), 3.25$ (dd, $J=3.0,15.4 \mathrm{~Hz}, 1 \mathrm{H}$ ), $2.91(\mathrm{dd}, J=5.3,13.2 \mathrm{~Hz}, 1 \mathrm{H}), 2.80(\mathrm{dd}, J=3.0,13.6 \mathrm{~Hz}$, $1 \mathrm{H}), 2.71(\mathrm{dd}, J=9.4,13.2 \mathrm{~Hz}, 1 \mathrm{H}), 1.46(\mathrm{~s}, 9 \mathrm{H}) ;{ }^{13} \mathrm{C} \mathrm{NMR}$ $\left(75 \mathrm{MHz}, \mathrm{CDCl}_{3}\right) \delta 170.9,169.2,155.2,152.1,149.6$, $148.7,141.9,137.0,136.1,135.5,134.1,133.7,129.3$ (2C), 128.7 (2C), 127.2, 125.9, 125.2, 108.7, 105.9, 81.5, 61.8, 60.6, 55.3, 41.9, 40.2, 37.3, 28.4 (3C); HRMS (ESI): $\mathrm{m} / \mathrm{z}$ calcd for $\mathrm{C}_{31} \mathrm{H}_{34} \mathrm{~N}_{4} \mathrm{O}_{9} \mathrm{Na}(\mathrm{M}+\mathrm{Na})^{+} 629.2223$; found 629.2217. For compound 9: Mp $160 \sim 163^{\circ} \mathrm{C}$; ${ }^{1} \mathrm{H}$ NMR $\left(300 \mathrm{MHz}, \mathrm{CDCl}_{3}\right) \delta 7.86(\mathrm{~s}, 1 \mathrm{H}), 7.49(\mathrm{~d}, J=7.5 \mathrm{~Hz}, 1 \mathrm{H})$, $7.32-7.20(\mathrm{~m}, 7 \mathrm{H}), 6.89(\mathrm{~d}, J=7.8 \mathrm{~Hz}, 1 \mathrm{H}), 6.33(\mathrm{~s}, 1 \mathrm{H})$, $5.59(\mathrm{br} \mathrm{s}, 1 \mathrm{H}), 5.32(\mathrm{~s}, 1 \mathrm{H}), 4.96(\mathrm{br} \mathrm{s}, 1 \mathrm{H}), 4.75(\mathrm{dd}$, $J=9.2,15.3 \mathrm{~Hz}, 1 \mathrm{H}), 4.74$ (br s, 1H), $4.45(\mathrm{~m}, 1 \mathrm{H}), 4.06$ (s, $3 \mathrm{H}), 3.64$ (dd, $J=4.1,13.7 \mathrm{~Hz}, 1 \mathrm{H}), 3.32(\mathrm{~d}, J=16.3 \mathrm{~Hz}$, $1 \mathrm{H}), 3.08(\mathrm{dd}, J=3.9,12.8 \mathrm{~Hz}, 1 \mathrm{H}), 2.90(\mathrm{~d}, J=12.8 \mathrm{~Hz}$, 1H), 2.81 (dd, $J=10.3,12.7 \mathrm{~Hz}, 1 \mathrm{H}), 1.53$ (s, 9H); HRMS (ESI): $m / z$ calcd for $\mathrm{C}_{31} \mathrm{H}_{34} \mathrm{~N}_{4} \mathrm{O}_{9} \mathrm{Na}(\mathrm{M}+\mathrm{Na})^{+}$629.2223; found 629.2213 .

\section{Compound 12}

To a solution of compound $8(60 \mathrm{mg}, 0.1 \mathrm{mmol})$ in $\mathrm{CH}_{2} \mathrm{Cl}_{2}$ $(4.0 \mathrm{ml})$ was added TFA $(2.0 \mathrm{ml})$ at $0^{\circ} \mathrm{C}$. After being stirred at the same temperature for 1.0 hour, the reaction mixture was concentrated to dryness under vacuum to afford compound $\mathbf{1 0}$ which was directly used for next reaction. To a solution of amine $\mathbf{1 0}$ and D- $N$-Boc Leucine $11(55 \mathrm{mg}$, $0.24 \mathrm{mmol})$ in DMF $(4 \mathrm{ml})$ was added DIPEA $(174 \mu 1$, $1.0 \mathrm{mmol})$ and HATU $(95 \mathrm{mg}, 0.25 \mathrm{mmol})$. The reaction mixture was stirred at room temperature for 12 hours before it was extracted with EtOAc. The organic phase was washed with $5 \%$ aqueous $\mathrm{HCl}$, saturated $\mathrm{NaHCO}_{3}$, brine, dried over $\mathrm{Na}_{2} \mathrm{SO}_{4}$, and concentrated under vacuum. The residue was purified by flash column chromatography ( $\mathrm{SiO}_{2}$, eluant: $\left.\mathrm{CH}_{2} \mathrm{Cl}_{2} / \mathrm{MeOH}=50 / 1\right)$ to afford tripeptide $(80 \mathrm{mg})$. To a solution of above tripeptide in $\mathrm{THF} / \mathrm{H}_{2} \mathrm{O}(3 / 1$, $6.0 \mathrm{ml})$ was added $\mathrm{LiOH}_{2} \mathrm{H}_{2} \mathrm{O}(17 \mathrm{mg}, 0.40 \mathrm{mmol})$ at $0^{\circ} \mathrm{C}$. After being stirred for 1.0 hour at $0^{\circ} \mathrm{C}$, the reaction mixture was acidified with $5 \% \mathrm{HCl}$ to $\mathrm{pH} 3 \sim 4$ and extracted with EtOAc. The combined organic phase was washed with 
brine, dried over $\mathrm{Na}_{2} \mathrm{SO}_{4}$, and concentrated under vacuum. The residue was purified by flash column chromatography $\left(\mathrm{SiO}_{2}\right.$, eluant: $\left.\mathrm{CH}_{2} \mathrm{Cl}_{2} / \mathrm{MeOH}=40 / 1\right)$ to afford $12(45 \mathrm{mg}$, $63 \%)$. Mp $150 \sim 153^{\circ} \mathrm{C} ;[\alpha]_{\mathrm{D}}^{23}+69.4\left(c 0.50, \mathrm{CHCl}_{3}\right)$; IR $\left(\mathrm{CHCl}_{3}\right) \mathrm{cm}^{-1}$ 3622, 3436, 3017, 2976, 1664 (brs), 1594, $1535,1496,1457,1369,1232,1201,1167,1046,877 ;{ }^{1} \mathrm{H}$ NMR $\left(300 \mathrm{MHz}, \mathrm{CDCl}_{3}\right) \delta 8.28(\mathrm{~s}, 1 \mathrm{H}), 7.67(\mathrm{~d}, J=8.7 \mathrm{~Hz}$, $1 \mathrm{H}), 7.45(\mathrm{dd}, J=2.3,8.7 \mathrm{~Hz}, 1 \mathrm{H}), 7.32 \sim 7.13(\mathrm{~m}, 5 \mathrm{H})$, $6.98(\mathrm{~d}, J=8.7 \mathrm{~Hz}, 1 \mathrm{H}), 6.80$ (d, $J=8.3 \mathrm{~Hz}, 1 \mathrm{H}), 6.39$ (d, $J=1.5 \mathrm{~Hz}, 1 \mathrm{H}), 5.65(\mathrm{dd}, J=3.4,9.4 \mathrm{~Hz}, 1 \mathrm{H}), 5.47$ (d, $J=1.5 \mathrm{~Hz}, 1 \mathrm{H}), 5.00$ (m, 1H), 4.97 (d, $J=7.2 \mathrm{~Hz}, 1 \mathrm{H}), 4.80$ (dd, $J=9.4,15.8 \mathrm{~Hz}, 1 \mathrm{H}), 4.37$ (m, 1H), 4.25 (dd, $J=7.2$, $14.3 \mathrm{~Hz}, 1 \mathrm{H}), 4.04$ (s, 3H), 3.57 (dd, $J=4.9,13.6 \mathrm{~Hz}, 1 \mathrm{H})$, 3.41 (dd, $J=3.4,15.8 \mathrm{~Hz}, 1 \mathrm{H}), 2.95$ (dd, $J=5.6,13.6 \mathrm{~Hz}$, $1 \mathrm{H}), 2.84(\mathrm{dd}, J=3.0,13.6 \mathrm{~Hz}, 1 \mathrm{H}), 2.78(\mathrm{dd}, J=9.0$, $13.6 \mathrm{~Hz}, 1 \mathrm{H}), 1.84 \sim 1.54(\mathrm{~m}, 3 \mathrm{H}), 1.49(\mathrm{~s}, 9 \mathrm{H}), 0.99(\mathrm{t}$, $J=6.8 \mathrm{~Hz}, 6 \mathrm{H}) ;{ }^{13} \mathrm{C} \mathrm{NMR}\left(75 \mathrm{MHz}, \mathrm{CDCl}_{3}\right) \delta 173.0,171.0$, $168.5,156.5,152.2,149.6,148.1,142.7,137.0,136.1$, 135.3, 134.3, 134.1, 129.4 (2C), 128.8 (2C), 127.3, 125.8, 125.7, 108.2, 105.5, 81.0, 61.9, 55.3, 53.9, 53.4, 42.0, 40.3, 40.0, 37.1, 28.4 (3C), 25.1, 22.9, 22.4; HRMS (ESI): $\mathrm{m} / \mathrm{z}$ calcd for $\mathrm{C}_{37} \mathrm{H}_{45} \mathrm{~N}_{5} \mathrm{O}_{10} \mathrm{Na}(\mathrm{M}+\mathrm{Na})^{+}$742.3064; found 742.3040 .

\section{Compound 13}

To a solution of compound $12(45 \mathrm{mg}, 0.063 \mathrm{mmol})$ in $\mathrm{CH}_{2} \mathrm{Cl}_{2}(2.0 \mathrm{ml})$ was added TFA $(1.0 \mathrm{ml})$ at $0^{\circ} \mathrm{C}$. After being stirred at the same temperature for 1.0 hour, the reaction mixture was concentrated to dryness under vacuum to afford amine which was directly used for next reaction. To a solution of amine and $N$-Boc glycine $(26 \mathrm{mg}$, $0.15 \mathrm{mmol})$ in DMF $(3 \mathrm{ml})$ was added DIPEA ( $44 \mu 1$, $0.25 \mathrm{mmol})$ and HATU $(60 \mathrm{mg}, 0.16 \mathrm{mmol})$. The reaction mixture was stirred at room temperature for 12 hours before it was extracted with EtOAc. The organic phase was washed with $5 \%$ aqueous $\mathrm{HCl}$, saturated $\mathrm{NaHCO}_{3}$, brine, dried over $\mathrm{Na}_{2} \mathrm{SO}_{4}$, and concentrated under vacuum. The residue was purified by flash column chromatography $\left(\mathrm{SiO}_{2}\right.$, eluant: $\left.\mathrm{CH}_{2} \mathrm{Cl}_{2} / \mathrm{MeOH}=40 / 1\right)$ to afford $\mathbf{1 3}(48 \mathrm{mg}$, $83 \%)$. Mp $131 \sim 133^{\circ} \mathrm{C} ;[\alpha]_{\mathrm{D}}^{23}+59.2\left(c 0.50, \mathrm{CHCl}_{3}\right)$; IR $\left(\mathrm{CHCl}_{3}\right)$ 3434, 3352, 3028, 2932, 2854, 1773, 1666, 1509, 1436, 1368, 1315, 1281, 1156, 998, $857 \mathrm{~cm}^{-1} ;{ }^{1} \mathrm{H} \mathrm{NMR}$ $\left(300 \mathrm{MHz}, \mathrm{CDCl}_{3}\right) \delta 8.03(\mathrm{~d}, J=1.5 \mathrm{~Hz}, 1 \mathrm{H}), 7.43(\mathrm{~m}, 2 \mathrm{H})$, $7.27 \sim 7.19(\mathrm{~m}, 4 \mathrm{H}), 7.08(\mathrm{~d}, J=6.8 \mathrm{~Hz}, 2 \mathrm{H}), 6.98(\mathrm{~d}$, $J=8.3 \mathrm{~Hz}, 1 \mathrm{H}), 6.90$ (br s, $1 \mathrm{H}), 6.77 \sim 6.70(\mathrm{~m}, 2 \mathrm{H}), 6.53$ (s, 1H), $5.86(\mathrm{~s}, 1 \mathrm{H}), 5.61$ (br s, 1H), $5.24(\mathrm{~m}, 1 \mathrm{H}), 4.89(\mathrm{~m}$, $1 \mathrm{H}), 4.60(\mathrm{~m}, 1 \mathrm{H}), 4.52(\mathrm{dd}, J=8.1,15.1 \mathrm{~Hz}, 1 \mathrm{H})$, $4.28 \sim 4.19(\mathrm{~m}, 3 \mathrm{H}), 3.93$ (s, 3H), 3.79 3.60 (m, 3H), 3.54 (dd, $J=4.5,13.6 \mathrm{~Hz}, 1 \mathrm{H}), 2.95 \sim 2.79(\mathrm{~m}, 3 \mathrm{H}), 1.80 \sim 1.65$ (m, 3H), 1.46 (s, 9H), 1.40 (s, 9H), 0.99 (d, $J=6.4 \mathrm{~Hz}, 3 \mathrm{H})$, $0.94(\mathrm{~d}, J=6.4 \mathrm{~Hz}, 3 \mathrm{H}) ;{ }^{13} \mathrm{C}$ NMR $\left(75 \mathrm{MHz}, \mathrm{CDCl}_{3}\right) \delta$
$172.6,171.6,171.3,168.9,168.5,156.5,155.8,153.4$, $147.9,143.9,142.7,140.3,137.4,136.0,134.5,134.1$, 129.7 (2C), 128.7 (2C), 127.2, 126.1, 125.5, 115.2, 111.5, $80.8,80.5,61.7,54.9,54.6,53.6,42.5,41.6,40.0,39.5$, 36.5, 29.8, 28.4 (3C), 28.3 (3C), 25.1, 23.1, 21.7; HRMS (ESI): $m / z$ calcd for $\mathrm{C}_{46} \mathrm{H}_{60} \mathrm{~N}_{7} \mathrm{O}_{14} \mathrm{Na}(\mathrm{M}+\mathrm{Na})^{+} 956.4018$; found 956.4022 .

\section{Compound 14}

To a solution of $\mathbf{1 3}(40 \mathrm{mg}, 0.043 \mathrm{mmol})$ in THF $\cdot \mathrm{H}_{2} \mathrm{O}(3 / 1$, $4.0 \mathrm{ml})$ was added $\mathrm{LiOH} \cdot \mathrm{H}_{2} \mathrm{O}(18 \mathrm{mg}, 0.43 \mathrm{mmol})$ at $0^{\circ} \mathrm{C}$. After being stirred for 1.0 hour at $0^{\circ} \mathrm{C}$, the reaction mixture was acidified with $5 \% \mathrm{HCl}$ to $\mathrm{pH} 3 \sim 4$ and extracted with EtOAc. The organic phase was washed with brine, dried over $\mathrm{Na}_{2} \mathrm{SO}_{4}$, and concentrated under vacuum. The residue was purified by flash column chromatography $\left(\mathrm{SiO}_{2}\right.$, eluant: $\left.\mathrm{CH}_{2} \mathrm{Cl}_{2} / \mathrm{MeOH}=40 / 1\right)$ to afford $14(35 \mathrm{mg}, 98 \%)$. Mp $158 \sim 160^{\circ} \mathrm{C} ;[\alpha]_{\mathrm{D}}^{23}+52.3\left(\right.$ c $\left.1.00, \mathrm{CHCl}_{3}\right)$; IR $\left(\mathrm{CHCl}_{3}\right)$ 3410, 3020, 2936, 1664 (br s), 1593, 1535, 1512, 1456, 1368, 1244, 1220, 1168, 1089, 1045, 994, 897, $857 \mathrm{~cm}^{-1}$; ${ }^{1} \mathrm{H}$ NMR (300 MHz, CD $\left.{ }_{3} \mathrm{OD}\right) \delta 8.25(\mathrm{~d}, J=2.1 \mathrm{~Hz}, 1 \mathrm{H})$, $7.38(\mathrm{dd}, J=2.3,8.5 \mathrm{~Hz}, 1 \mathrm{H}), 7.24 \sim 7.07(\mathrm{~m}, 5 \mathrm{H}), 7.06(\mathrm{~d}$, $J=8.5 \mathrm{~Hz}, 1 \mathrm{H}), 6.37$ (d, $J=1.9 \mathrm{~Hz}, 1 \mathrm{H}), 5.47$ (s, 1H), 4.67 $(\mathrm{m}, 1 \mathrm{H}), 4.64(\mathrm{~d}, J=15.8 \mathrm{~Hz}, 1 \mathrm{H}), 4.50(\mathrm{dd}, J=5.7,8.9 \mathrm{~Hz}$, $1 \mathrm{H}), 4.42(\mathrm{t}, J=7.0 \mathrm{~Hz}, 1 \mathrm{H}), 3.90(\mathrm{~s}, 3 \mathrm{H}), 3.79(\mathrm{~d}$, $J=4.7 \mathrm{~Hz}, 2 \mathrm{H}), 3.46$ (d, $J=15.8 \mathrm{~Hz}, 1 \mathrm{H}), 3.43$ (dd, $J=5.7$, $14.3 \mathrm{~Hz}, 1 \mathrm{H}), 3.03(\mathrm{dd}, J=2.6,14.3 \mathrm{~Hz}, 1 \mathrm{H}), 2.83$ (d, $J=7.0 \mathrm{~Hz}, 2 \mathrm{H}), 1.75 \sim 1.58(\mathrm{~m}, 3 \mathrm{H}), 1.41(\mathrm{~s}, 9 \mathrm{H}), 0.97(\mathrm{~d}$, $J=6.2 \mathrm{~Hz}, 3 \mathrm{H}), 0.94(\mathrm{~d}, J=6.2 \mathrm{~Hz}, 3 \mathrm{H}) ;{ }^{13} \mathrm{C} \mathrm{NMR}$ $\left(75 \mathrm{MHz}, \mathrm{CD}_{3} \mathrm{OD}\right) \delta 175.6,173.0,172.6,170.6,158.5$, $154.3,152.2,149.4,144.2,137.7,137.4,137.0,135.7$, 135.6, 130.7 (2C), 129.4 (2C), 127.9, 127.1, 127.0, 110.0, $105.9,80.7,61.7,56.3,55.7,53.7,44.6,42.6,41.2,40.8$, 36.8, 28.7 (3C), 26.1, 23.4, 22.2; HRMS (ESI): $\mathrm{m} / \mathrm{z}$ calcd for $\mathrm{C}_{39} \mathrm{H}_{48} \mathrm{~N}_{6} \mathrm{O}_{11} \mathrm{Na}(\mathrm{M}+\mathrm{Na})^{+}$799.3279; found 799.3289.

\section{Compound 16}

To a solution of 1,3,4,6-tetra-O-acetyl-2- $N$-lauroyl-2amino-2-deoxy-2-D-glucopyranose $(85 \mathrm{mg}, 0.16 \mathrm{mmol})$ in $\mathrm{AcOH}(2 \mathrm{ml})$ was added $33 \% \mathrm{HBr} / \mathrm{AcOH}(0.9 \mathrm{ml})$ at room temperature [14]. After being stirred for 3 hours at room temperature, the reaction mixture was diluted with icewater and it was extracted with $\mathrm{CH}_{2} \mathrm{Cl}_{2}$. The combined organic phases were washed with cooled aqueous $\mathrm{NaHCO}_{3}$ and brine. The solvent was concentrated to about $1 \mathrm{ml}$ under vacuum below $30^{\circ} \mathrm{C}$ and the resulting solution was immediately used for next reaction. To the above solution was added compound $\mathbf{1 4}(18 \mathrm{mg}, 0.023 \mathrm{mmol})$, $10 \%$ aqueous $\mathrm{Na}_{2} \mathrm{CO}_{3}(1.0 \mathrm{ml})$ and catalytic amount of $(n \mathrm{Bu})_{4} \mathrm{NHSO}_{4}$. After being stirred at room temperature for 4 hours, the reaction mixture was acidified with citric 
acid to $\mathrm{pH} 4 \sim 5$ and the two phases were separated. The aqueous phase was extracted with $\mathrm{CH}_{2} \mathrm{Cl}_{2}$. The combined organic phases were washed with brine, dried over $\mathrm{Na}_{2} \mathrm{SO}_{4}$, and concentrated under vacuum. The residue was purified by flash column chromatography $\left(\mathrm{SiO}_{2}\right.$, eluant: $\left.\mathrm{CH}_{2} \mathrm{Cl}_{2} / \mathrm{MeOH}=40 / 1\right)$ to afford $16(22 \mathrm{mg}, 76 \%)$. Mp $>230^{\circ} \mathrm{C} ;[\alpha]_{\mathrm{D}}^{23}+50.8\left(c 1.00, \mathrm{CHCl}_{3}\right)$; IR $\left(\mathrm{CHCl}_{3}\right) 3431$, 2928, 2855, 1747, 1667, 1537, 1508, 1435, 1368, 1258, 1161, 1049, 1045, 1040, 902, $857 \mathrm{~cm}^{-1} ;{ }^{1} \mathrm{H}$ NMR $\left(300 \mathrm{MHz}, \mathrm{CD}_{3} \mathrm{OD}\right) \delta 8.27(\mathrm{~d}, J=2.3 \mathrm{~Hz}, 1 \mathrm{H}), 7.40$ (dd, $J=2.3,8.7 \mathrm{~Hz}, 1 \mathrm{H}), 7.24 \sim 7.06(\mathrm{~m}, 6 \mathrm{H}), 6.71(\mathrm{~d}, J=1.9 \mathrm{~Hz}$, $1 \mathrm{H}), 5.71(\mathrm{~s}, 1 \mathrm{H}), 5.35(\mathrm{dd}, J=9.4,10.6 \mathrm{~Hz}, 1 \mathrm{H}), 5.28(\mathrm{~d}$, $J=8.7 \mathrm{~Hz}, 1 \mathrm{H}), 5.06(\mathrm{t}, J=9.8 \mathrm{~Hz}, 1 \mathrm{H}), 4.67(\mathrm{~d}, J=15.8 \mathrm{~Hz}$, $1 \mathrm{H}), 4.67$ (dd, $J=2.3,5.7 \mathrm{~Hz}, 1 \mathrm{H}), 4.51(\mathrm{dd}, J=6.0,9.0 \mathrm{~Hz}$, $1 \mathrm{H}), 4.41(\mathrm{t}, J=6.8 \mathrm{~Hz}, 1 \mathrm{H}), 4.30 \sim 4.14(\mathrm{~m}, 3 \mathrm{H}), 3.98(\mathrm{~m}$, $1 \mathrm{H}), 3.84(\mathrm{~s}, 3 \mathrm{H}), 3.78(\mathrm{~d}, J=6.4 \mathrm{~Hz}, 2 \mathrm{H}), 3.51(\mathrm{~d}$, $J=15.8 \mathrm{~Hz}, 1 \mathrm{H}), 3.44$ (dd, $J=5.7,14.0 \mathrm{~Hz}, 1 \mathrm{H}), 3.05$ (dd, $J=2.3,14.0 \mathrm{~Hz}, 1 \mathrm{H}), 2.83(\mathrm{t}, J=6.8 \mathrm{~Hz}, 2 \mathrm{H}), 2.17$ (t, $J=7.5 \mathrm{~Hz}, 2 \mathrm{H}), 2.02(\mathrm{~s}, 3 \mathrm{H}), 2.01(\mathrm{~s}, 3 \mathrm{H}), 2.00$ (s, 3H), $1.75 \sim 1.50(\mathrm{~m}, 5 \mathrm{H}), 1.42(\mathrm{~s}, 9 \mathrm{H}), 1.35 \sim 1.20$ (br s, $16 \mathrm{H})$, $0.98(\mathrm{~d}, J=6.0 \mathrm{~Hz}, 3 \mathrm{H}), 0.94(\mathrm{~d}, J=6.0 \mathrm{~Hz}, 3 \mathrm{H}), 0.87$ (t, $J=6.8 \mathrm{~Hz}, 3 \mathrm{H}) ;{ }^{13} \mathrm{C}$ NMR $\left(75 \mathrm{MHz}, \mathrm{CD}_{3} \mathrm{OD}\right) \delta 176.6$, $175.6,173.1,172.7,172.3,171.7,171.3,170.6,158.5$, $154.6,152.2,149.2,144.1,139.5,137.9,137.4,135.9$, 135.6, 130.7 (2C), 129.4 (2C), 127.9, 127.2, 126.9, 111.2, $109.5,100.6,80.8,73.9,73.2,70.2,63.3,62.0,56.3,55.7$, $55.3,53.6,44.6,42.7,41.2,40.8,37.5,36.8,33.1,30.8$ (2C), 30.6, 30.5 (3C), 30.3, 28.8 (3C), 27.0, 26.1, 23.8, 23.4, 22.2, 20.8, 20.7, 14.5; HRMS (ESI): $\mathrm{m} / \mathrm{z}$ calcd for $\mathrm{C}_{63} \mathrm{H}_{87} \mathrm{~N}_{7} \mathrm{O}_{19} \mathrm{Na}(\mathrm{M}+\mathrm{Na})^{+}$1268.5954; found 1268.5955.

\section{Compound 2c}

To a solution of compound $\mathbf{1 6}(20 \mathrm{mg}, 1.6 \mu \mathrm{mol})$ in $\mathrm{THF} / \mathrm{H}_{2} \mathrm{O}(3 / 1,2.0 \mathrm{ml})$ was added LiOH. $\mathrm{H}_{2} \mathrm{O}(16 \mathrm{mg}$, $0.38 \mathrm{mmol})$ at $0^{\circ} \mathrm{C}$. After being stirred for 1.0 hour at $0^{\circ} \mathrm{C}$, the reaction mixture was acidified with $5 \% \mathrm{HCl}$ to $\mathrm{pH}$ $3 \sim 4$ and extracted with EtOAc. The combined organic phase was washed with brine, dried over $\mathrm{Na}_{2} \mathrm{SO}_{4}$, and concentrated under vacuum to afford compound acid, which proved to be of sufficient purity and was used directly for next step. To a solution of above acid in $\mathrm{CH}_{2} \mathrm{Cl}_{2}$ $(1.0 \mathrm{ml})$ was added TFA $(0.5 \mathrm{ml})$ at $0^{\circ} \mathrm{C}$. After being stirred at the same temperature for 1.0 hour, the reaction mixture was concentrated to dryness under vacuum to afford compound 2c $(13 \mathrm{mg}, 80 \%)$. Mp $>230^{\circ} \mathrm{C} ;[\alpha]_{\mathrm{D}}^{23}+57.6(\mathrm{c}$ $0.30, \mathrm{MeOH}) ;{ }^{1} \mathrm{H}$ NMR $\left(300 \mathrm{MHz}, \mathrm{CD}_{3} \mathrm{OD}\right) \delta 8.30(\mathrm{~d}$, $J=2.3 \mathrm{~Hz}, 1 \mathrm{H}), 7.42(\mathrm{dd}, J=2.3,8.7 \mathrm{~Hz}, 1 \mathrm{H}), 7.26 \sim 7.10$ (m, 5H), 7.09 (d, $J=8.7 \mathrm{~Hz}, 1 \mathrm{H}), 6.72(\mathrm{~d}, J=1.9 \mathrm{~Hz}, 1 \mathrm{H})$, $5.59(\mathrm{~s}, 1 \mathrm{H}), 5.08(\mathrm{~d}, J=8.3 \mathrm{~Hz}, 1 \mathrm{H}), 4.69(\mathrm{dd}, J=2.3$, $5.7 \mathrm{~Hz}, 1 \mathrm{H}), 4.58(\mathrm{~d}, J=15.8 \mathrm{~Hz}, 1 \mathrm{H}), 4.46(\mathrm{t}, J=6.8 \mathrm{~Hz}$, $1 \mathrm{H}), 4.42(\mathrm{dd}, J=5.7,9.0 \mathrm{~Hz}, 1 \mathrm{H}), 3.93(\mathrm{dd}, J=8.3$,
$10.2 \mathrm{~Hz}, 1 \mathrm{H}), 3.89(\mathrm{~m}, 1 \mathrm{H}), 3.86(\mathrm{~s}, 3 \mathrm{H}), 3.71 \sim 3.57(\mathrm{~m}$, $3 \mathrm{H}), 3.56(\mathrm{~d}, J=15.8 \mathrm{~Hz}, 1 \mathrm{H}), 3.46 \sim 3.38(\mathrm{~m}, 4 \mathrm{H}), 3.07$ (dd, $J=2.3,14.3 \mathrm{~Hz}, 1 \mathrm{H}), 2.87$ (d, $J=7.2 \mathrm{~Hz}, 2 \mathrm{H}), 2.24$ (t, $J=7.5 \mathrm{~Hz}, 2 \mathrm{H}), 1.80 \sim 1.55(\mathrm{~m}, 5 \mathrm{H}), 1.39 \sim 1.20(\mathrm{~m}, 16 \mathrm{H})$, $1.01(\mathrm{~d}, J=6.0 \mathrm{~Hz}, 3 \mathrm{H}), 0.97$ (d, $J=6.0 \mathrm{~Hz}, 3 \mathrm{H}), 0.87$ (t, $J=7.2 \mathrm{~Hz}, 3 \mathrm{H}) ;{ }^{13} \mathrm{C}$ NMR $\left(75 \mathrm{MHz}, \mathrm{CD}_{3} \mathrm{OD}\right) \delta 176.9$, $175.7,173.2,170.3,168.6,154.2,152.9,149.1,144.2$, $139.1,138.6,137.5,136.1,135.3,130.6$ (2C), 129.4 (2C), $127.9,127.1,127.0,110.7,108.1,101.2,78.5,75.8,72.2$, $62.7,62.0,57.4,56.0,55.5,55.1,42.7,41.5,41.0$ (2C), 37.7, 36.6, 33.1, 30.8 (2C), 30.7, 30.6, 30.5, 30.4, 27.0, 26.1, 23.8, 23.3, 22.1, 14.5; HRMS (ESI): $\mathrm{m} / \mathrm{z}$ calcd for $\mathrm{C}_{52} \mathrm{H}_{73} \mathrm{~N}_{7} \mathrm{O}_{14} \mathrm{Na}(\mathrm{M}+\mathrm{Na})^{+}$1042.5113; found 1042.5106.

\section{Compound 2a}

Mp $155 \sim 157^{\circ} \mathrm{C} ;[\alpha]_{\mathrm{D}}^{23}+58.4(c 0.25, \mathrm{MeOH}) ;{ }^{1} \mathrm{H}$ NMR $\left(300 \mathrm{MHz}, \mathrm{CD}_{3} \mathrm{OD}\right) \delta 8.27(\mathrm{~d}, J=2.1 \mathrm{~Hz}, 1 \mathrm{H}), 7.41(\mathrm{dd}$, $J=2.3,8.5 \mathrm{~Hz}, 1 \mathrm{H}), 7.26 \sim 7.12(\mathrm{~m}, 5 \mathrm{H}), 7.11(\mathrm{~d}, J=8.5 \mathrm{~Hz}$, $1 \mathrm{H}), 6.35(\mathrm{~d}, J=2.1 \mathrm{~Hz}, 1 \mathrm{H}), 5.38(\mathrm{~d}, J=2.1 \mathrm{~Hz}, 1 \mathrm{H}), 4.69$ (dd, $J=2.4,6.0 \mathrm{~Hz}, 1 \mathrm{H}), 4.57(\mathrm{~d}, J=15.8 \mathrm{~Hz}, 1 \mathrm{H}), 4.46(\mathrm{t}$, $J=7.2 \mathrm{~Hz}, 1 \mathrm{H}), 4.40$ (dd, $J=5.5,9.1 \mathrm{~Hz}, 1 \mathrm{H}), 3.91$ (s, 3H), $3.87(\mathrm{~s}, 2 \mathrm{H}), 3.47(\mathrm{~d}, J=15.8 \mathrm{~Hz}, 1 \mathrm{H}), 3.43(\mathrm{dd}, J=6.0$, $14.3 \mathrm{~Hz}, 1 \mathrm{H}), 3.06(\mathrm{dd}, J=2.4,14.3 \mathrm{~Hz}, 1 \mathrm{H}), 2.87$ (d, $J=7.2 \mathrm{~Hz}, 1 \mathrm{H}), 2.86(\mathrm{~d}, J=7.2 \mathrm{~Hz}, 1 \mathrm{H}), 1.80 \sim 1.65$ (m, $3 \mathrm{H}), 1.02(\mathrm{~d}, J=6.0 \mathrm{~Hz}, 3 \mathrm{H}), 0.98(\mathrm{~d}, J=6.0 \mathrm{~Hz}, 3 \mathrm{H}) ;{ }^{13} \mathrm{C}$ NMR $\left(75 \mathrm{MHz}, \mathrm{CD}_{3} \mathrm{OD}\right) \delta 175.6,173.2,170.2,168.8$, $154.1,152.4,149.1,144.4,138.5,137.5,136.9,136.0$, 135.3, 130.6 (2C), 129.4 (2C), 127.9, 127.1, 126.8, 109.7, 105.0, 61.6, 55.9, 55.6, 55.4, 42.6, 41.5, 41.0, 40.9, 36.6, 26.1, 23.3, 22.0; HRMS (ESI): $m / z$ calcd for $\mathrm{C}_{34} \mathrm{H}_{41} \mathrm{~N}_{6} \mathrm{O}_{9}$ $(\mathrm{M}+\mathrm{H})^{+}$677.2935; found 677.2932.

\section{Compound 2b}

Mp $173 \sim 175^{\circ} \mathrm{C} ;[\alpha]_{\mathrm{D}}^{23}+68.9(c 0.35, \mathrm{MeOH}) ;{ }^{1} \mathrm{H}$ NMR $\left(300 \mathrm{MHz}, \mathrm{CD}_{3} \mathrm{OD}\right) \delta 8.36(\mathrm{~d}, J=2.3 \mathrm{~Hz}, 1 \mathrm{H}), 7.46(\mathrm{dd}$, $J=2.3,8.5 \mathrm{~Hz}, 1 \mathrm{H}), 7.26 \sim 7.12(\mathrm{~m}, 6 \mathrm{H}), 6.70(\mathrm{~d}, J=2.0 \mathrm{~Hz}$, $1 \mathrm{H}), 5.88(\mathrm{~d}, J=2.0 \mathrm{~Hz}, 1 \mathrm{H}), 4.69(\mathrm{dd}, J=2.5,6.0 \mathrm{~Hz}, 1 \mathrm{H})$, $4.61(\mathrm{~d}, J=16.1 \mathrm{~Hz}, 1 \mathrm{H}), 4.48(\mathrm{t}, J=7.0 \mathrm{~Hz}, 1 \mathrm{H}), 4.42(\mathrm{dd}$, $J=5.3,9.0 \mathrm{~Hz}, 1 \mathrm{H}), 4.20$ (s, 2H), 3.96 (s, 3H), 3.87 (s, 2H), $3.60(\mathrm{~d}, J=16.1 \mathrm{~Hz}, 1 \mathrm{H}), 3.45$ (dd, $J=6.0,14.3 \mathrm{~Hz}, 1 \mathrm{H})$, 3.10 (dd, $J=2.5,14.3 \mathrm{~Hz}, 1 \mathrm{H}), 2.88(\mathrm{~d}, J=7.0 \mathrm{~Hz}, 2 \mathrm{H})$, $1.81 \sim 1.62(\mathrm{~m}, 3 \mathrm{H}), 1.01(\mathrm{~d}, J=6.2 \mathrm{~Hz}, 3 \mathrm{H}), 0.97$ (d, $J=6.2 \mathrm{~Hz}, 3 \mathrm{H}) ;{ }^{13} \mathrm{C} \mathrm{NMR}\left(75 \mathrm{MHz}, \mathrm{CDCl}_{3}\right) \delta 175.7,173.4$, $170.3,168.7,167.2,154.2,148.3,144.7,144.1,140.9$, $138.9,137.5,136.8,135.5,130.6(2 \mathrm{C}), 129.5(2 \mathrm{C}), 127.9$, $127.3,126.8,115.6,112.5,62.0,56.1,55.5,55.2,42.2$, 41.5, 41.0 (2C), 36.6, 30.8, 26.1, 23.3, 22.1; HRMS (ESI): $m / z$ calcd for $\mathrm{C}_{36} \mathrm{H}_{44} \mathrm{~N}_{7} \mathrm{O}_{10}(\mathrm{M}+\mathrm{H})^{+} 734.3150$; found 734.3160 . 


\section{Compound 3a}

Mp $165 \sim 167^{\circ} \mathrm{C} ;[\alpha]_{\mathrm{D}}^{23}+161.8($ c $0.30, \mathrm{MeOH}) ;{ }^{1} \mathrm{H}$ NMR $\left(300 \mathrm{MHz}, \mathrm{CD}_{3} \mathrm{OD}\right) \delta 8.31(\mathrm{~d}, J=2.3 \mathrm{~Hz}, 1 \mathrm{H}), 7.41$ (dd, $J=2.3,8.3 \mathrm{~Hz}, 1 \mathrm{H}), 7.26 \sim 7.09(\mathrm{~m}, 6 \mathrm{H}), 6.37(\mathrm{~d}, J=2.2 \mathrm{~Hz}$, $1 \mathrm{H}), 5.46(\mathrm{~d}, J=2.1 \mathrm{~Hz}, 1 \mathrm{H}), 4.68(\mathrm{dd}, J=2.6,5.2 \mathrm{~Hz}, 1 \mathrm{H})$, $4.62(\mathrm{~d}, J=15.8 \mathrm{~Hz}, 1 \mathrm{H}), 4.50$ (t, $J=7.4 \mathrm{~Hz}, 1 \mathrm{H}), 4.43$ (dd, $J=5.7,8.3 \mathrm{~Hz}, 1 \mathrm{H}), 3.89$ (s, $3 \mathrm{H}), 3.68$ (d, $J=15.8 \mathrm{~Hz}, 1 \mathrm{H})$, 3.48 (d, $J=15.8 \mathrm{~Hz}, 1 \mathrm{H}), 3.45(\mathrm{~d}, J=15.8 \mathrm{~Hz}, 1 \mathrm{H})$, $3.47 \sim 3.42(\mathrm{~m}, 1 \mathrm{H}), 3.07$ (dd, $J=2.6,14.3 \mathrm{~Hz}, 1 \mathrm{H}), 2.86$ (dd, $J=5.6,13.2 \mathrm{~Hz}, 1 \mathrm{H}), 2.76$ (dd, $J=8.3,13.2 \mathrm{~Hz}, 1 \mathrm{H})$, $1.79 \sim 1.63(\mathrm{~m}, 3 \mathrm{H}), 1.05(\mathrm{~d}, J=6.4 \mathrm{~Hz}, 3 \mathrm{H}), 1.00(\mathrm{~d}$, $J=6.0 \mathrm{~Hz}, 3 \mathrm{H}) ;{ }^{13} \mathrm{C}$ NMR $\left(75 \mathrm{MHz}, \mathrm{CD}_{3} \mathrm{OD}\right) \delta 173.9$, $172.9,170.8,168.1,154.4,152.5,149.1,144.4,137.7$, 137.6, 137.0, 135.7, 135.1, 130.6 (2C), 129.5 (2C), 128.0, $127.2,127.1,109.9,105.3,61.7,56.4,56.0,53.7,42.4$, 41.5, 40.7, 39.8, 36.6, 26.0, 23.3, 22.5; HRMS (ESI): $\mathrm{m} / \mathrm{z}$ calcd for $\mathrm{C}_{34} \mathrm{H}_{41} \mathrm{~N}_{6} \mathrm{O}_{9}(\mathrm{M}+\mathrm{H})^{+}$677.2935; found 677.2938.

\section{Compound $\mathbf{3 b}$}

Mp $167 \sim 169^{\circ} \mathrm{C} ;[\alpha]_{\mathrm{D}}^{23}+139.1($ c $0.40, \mathrm{MeOH}) ;{ }^{1} \mathrm{H}$ NMR $\left(300 \mathrm{MHz}, \mathrm{CD}_{3} \mathrm{OD}\right) \delta 8.37(\mathrm{~d}, J=2.3 \mathrm{~Hz}, 1 \mathrm{H}), 7.46(\mathrm{dd}$, $J=2.3,8.5 \mathrm{~Hz}, 1 \mathrm{H}), 7.26 \sim 7.09(\mathrm{~m}, 6 \mathrm{H}), 6.72(\mathrm{~d}, J=2.1 \mathrm{~Hz}$, $1 \mathrm{H}), 5.96(\mathrm{~d}, J=2.0 \mathrm{~Hz}, 1 \mathrm{H}), 4.69$ (dd, $J=2.8,5.4 \mathrm{~Hz}, 1 \mathrm{H})$, 4.67 (d, $J=16.2 \mathrm{~Hz}, 1 \mathrm{H}), 4.49$ (t, $J=8.1 \mathrm{~Hz}, 1 \mathrm{H}), 4.46$ (dd, $J=5.7,8.1 \mathrm{~Hz}, 1 \mathrm{H}), 4.20(\mathrm{~s}, 2 \mathrm{H}), 3.94(\mathrm{~s}, 3 \mathrm{H}), 3.69$ (d, $J=16.1 \mathrm{~Hz}, 1 \mathrm{H}), 3.56$ (d, $J=16.1 \mathrm{~Hz}, 1 \mathrm{H}), 3.51 \sim 3.45$ (m, 1H), 3.48 (d, $J=16.2 \mathrm{~Hz}, 1 \mathrm{H}), 3.09$ (dd, $J=2.8,14.3 \mathrm{~Hz}$, $1 \mathrm{H}), 2.87(\mathrm{dd}, J=5.7,13.3 \mathrm{~Hz}, 1 \mathrm{H}), 2.77(\mathrm{dd}, J=8.1$, $13.3 \mathrm{~Hz}, 1 \mathrm{H}), 1.79 \sim 1.64(\mathrm{~m}, 3 \mathrm{H}), 1.05(\mathrm{~d}, J=6.0 \mathrm{~Hz}, 3 \mathrm{H})$, $1.00(\mathrm{~d}, J=6.0 \mathrm{~Hz}, 3 \mathrm{H}) ;{ }^{13} \mathrm{C}$ NMR $\left(75 \mathrm{MHz}, \mathrm{CDCl}_{3}\right) \delta$ $174.1,173.1,170.7,168.1,167.2,154.5,148.3,144.7$, $144.2,141.0,138.2,137.5,136.5,135.3,130.6(2 \mathrm{C}), 129.5$ (2C), 128.0, 127.5, 126.8, 115.7, 112.8, 62.0, 56.4, 56.0, 53.8, 42.0, 41.4, 41.0, 40.7, 40.0, 36.6, 26.0, 23.3, 22.5; HRMS (ESI): $m / z$ calcd for $\mathrm{C}_{36} \mathrm{H}_{44} \mathrm{~N}_{7} \mathrm{O}_{10}(\mathrm{M}+\mathrm{H})^{+}$ 734.3150; found 734.3163 .

\section{Compound 3c}

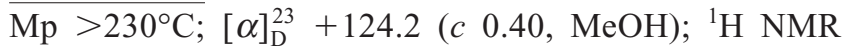
$\left(300 \mathrm{MHz}, \mathrm{CD}_{3} \mathrm{OD}\right) \delta 8.30(\mathrm{~d}, J=2.3 \mathrm{~Hz}, 1 \mathrm{H}), 7.42$ (dd, $J=2.3,8.7 \mathrm{~Hz}, 1 \mathrm{H}), 7.26 \sim 7.08(\mathrm{~m}, 6 \mathrm{H}), 6.74(\mathrm{~s}, 1 \mathrm{H}), 5.66$ (s, 1H), 5.10 (d, $J=8.7 \mathrm{~Hz}, 1 \mathrm{H}), 4.69$ (dd, $J=2.6,5.3 \mathrm{~Hz}$, 1H), $4.63(\mathrm{~d}, J=15.8 \mathrm{~Hz}, 1 \mathrm{H}), 4.49$ (t, $J=7.9 \mathrm{~Hz}, 1 \mathrm{H}), 4.45$ (dd, $J=5.7,8.3 \mathrm{~Hz}, 1 \mathrm{H}), 3.93 \sim 3.87(\mathrm{~m}, 2 \mathrm{H}), 3.84(\mathrm{~s}, 3 \mathrm{H})$, $3.72 \sim 3.37(\mathrm{~m}, 8 \mathrm{H}), 3.06(\mathrm{dd}, J=2.3,13.9 \mathrm{~Hz}, 1 \mathrm{H}), 2.86$ (dd, $J=5.7,13.6 \mathrm{~Hz}, 1 \mathrm{H}), 2.76(\mathrm{dd}, J=8.3,13.6 \mathrm{~Hz}, 1 \mathrm{H})$, 2.24 (t, $J=7.5 \mathrm{~Hz}, 2 \mathrm{H}), 1.78 \sim 1.53(\mathrm{~m}, 5 \mathrm{H}), 1.38 \sim 1.20(\mathrm{~m}$, $16 \mathrm{H}), 1.06(\mathrm{~d}, J=5.7 \mathrm{~Hz}, 3 \mathrm{H}), 1.03(\mathrm{~d}, J=5.7 \mathrm{~Hz}, 3 \mathrm{H}), 0.87$ $(\mathrm{t}, J=6.8 \mathrm{~Hz}, 3 \mathrm{H}) ;{ }^{13} \mathrm{C}$ NMR $\left(75 \mathrm{MHz}, \mathrm{CD}_{3} \mathrm{OD}\right) \delta 176.9$, $174.1,173.0,170.7,168.1,154.5,152.9,149.1,144.2$, $139.3,138.0,137.6,135.9,135.1,130.6$ (2C), 129.5 (2C),
$128.0,127.3,127.0,111.0,108.5,101.2,78.5,75.7,72.2$, $62.8,62.0,57.4,56.3,56.0,53.8,42.5,41.5,40.7,40.0$, $37.7,36.6,33.1,30.8$ (2C), 30.6, 30.5 (2C), 30.4, 26.9, 26.0, 23.8, 23.3, 22.5, 14.5; HRMS (ESI): $\mathrm{m} / \mathrm{z}$ calcd for $\mathrm{C}_{52} \mathrm{H}_{74} \mathrm{~N}_{7} \mathrm{O}_{14}(\mathrm{M}+\mathrm{H})^{+}$1020.5294; found 1020.5276 .

Acknowledgement Financial supports from Vicuron Pharmaceuticals (Post-Doctoral Fellowships to Dr. Y. Jia,), CNRS and this institute are gratefully acknowledged.

\section{References}

1. Williams DH, Bardsley B. The vancomycin group of antibiotics and the fight against resistant bacteria. Angew Chem Int Ed 38: 1172-1193 (1999)

2. Hubbard BK, Walsh CT. Vancomycin assembly: Nature's way. Angew Chem Int Ed 42: 730-765 (2003)

3. Süssmuth RD. Vancomycin resistanct: small molecule approaches targeting the bacterial cell wall biosynthesis. ChemBioChem 3: 295-298 (2002)

4. Kahne D, Leimkuhler C, Lu W, Walsh, CT. Glycopeptide and lipoglycopeptide antibiotics. Chem Rev 105: 425-448 (2005)

5. Malabarba A, Nicas TI, Thompson RC. Structural modifications of glycopeptide antibiotics. Med Res Rev 17: 69-137 (1997)

6. Zhu J. Recent developments for reversing the glycopeptideresistant pathogens Expert. Opin Ther Pat 9: 1005-1019 (1999)

7. Nagarajan R, Schabel AA, Occolowitz JL, Counter FT, Ott JL, Felty-Duckworth AM. Synthesis and antibacterial evaluation of $N$-alkyl vancomycins. J Antibiot 42: 63-72 (1989)

8. Jabés D, Candiani C, Romanó G, Brunati C, Riva M, Cavaleri M. Antimicrob Agents Chemother 48: 1118-1123 (2004)

9. Williams DH, Maguire AJ, Tsuzuki W, Westwell MS. An analysis of the origins of a cooperative binding energy of dimerization. Science 280: 711-714 (1998)

10. Ge M, Chen Z, Onishi HR, Kohler J, Silver LL, Kerns R, Fukuzawa S, Thompson C, Kahne D. Vancomycin derivatives that inhibit peptidoglycan biosynthesis without binding D-Ala-D-Ala. Science 284: 507-511 (1999)

11. Leimkuhler C, Chen L, Barrett D, Panzone G, Sun B, Falcone B, Oberthür M, Donadio S, Walker S, Kahne D. Differential inhibition of Staphylococcus aureus PBP2 by glycopeptide antibiotics. J Am Chem Soc 127: 3250-3251 (2005)

12. Ma N, Jia Y, Liu Z, Gonzalez-Zamora E, Bois-Choussy M, Malabarba A, Brunati C, Zhu J. Design and synthesis of macrocycles active against vancomycin-resistance enterococci (VRE): the interplay between D-ala-D-lac binding and hydrophobic effect. Bioorg Med Chem Lett 15: 743-746 (2005) 
13. Jia Y, Gonzalez-Zamora E, Ma N, Liu Z, Bois-Choussy M, Malabarba A, Brunati, C, Zhu J. Identification of synthetic compounds active against VRE: the role of the lipidated aminoglucose and the structure of glycopeptide binding pocket. Bioorg Med Chem Lett 15: 4594-4599 (2005)

14. Jia Y, Ma N, Liu Z, Bois-Choussy M, Gonzalez-Zamora E, Malabarba A, Brunati C, Zhu J. Design and synthesis of simple macrocycles active against vancomycin-resistant enterococci (VRE). Chem-A Eur J 12: 5334-5351 (2006)

15. Zhu J. $\mathrm{S}_{\mathrm{N}} \mathrm{Ar}$ based macrocyclization via biaryl ether formation: application in natural product synthesis. Synlett 133-144 (1997)

16. Nicolaou $\mathrm{KC}$, Boddy $\mathrm{CNC}$, Bräse $\mathrm{S}$, Winssinger $\mathrm{N}$. Chemistry, biology, and medicine of the glycopeptide antibiotics. Angew Chem Int Ed 38: 2096-2152 (1999)

17. Beugelmans R, Bois-Choussy M, Vergne C, Buillon JP, Zhu J. Synthesis of model bicyclic C-O-D-O-E ring of vancomycine by a one-pot, double $\mathrm{S}_{\mathrm{N}} \mathrm{Ar}$ based macrocyclization. J Chem Soc Chem Commun 1029-1030 (1996)

18. Schmidt RR. New methods for the synthesis of glycosides and oligosaccharides-Are there alternatives to the Koenigs-
Knorr Method? Angew Chem Int Ed 25: 212-235 (1986)

19. Islas-Gonzalez G, Zhu J. A unified strategy toward the synthesis of acerogenin type macrocycles: total syntheses of acerogenin A, B, C, L and aceroside IV. J Org Chem 64: 914-924 (1999)

20. $\mathrm{Xu} \mathrm{R}$, Greiveldinger G, Marenus LE, Cooper A, Ellman JA. Combinatorial library approach for the identification of synthetic receptors targeting vancomycin-resistant bacteria. J Am Chem Soc 121: 4898-4899 (1999)

21. Crowley BM, Boger DL. Total synthesis and evaluation of $\left[\psi\left[\mathrm{CH}_{2} \mathrm{NH}\right] \mathrm{Tpg}^{4}\right]$ vancomhycin aglycon: reengineering vancomycin for dual D-Ala-D-Ala and D-Ala-D-Lac binding. J Am Chem Soc 128: 2885-2892 (2006)

22. Görlitzer J, Gale TF, Williams DH. Attempted introduction of a fourth amide $\mathrm{NH}$ into the carboxylate-binding pocket of glycopeptide antibiotics. J Chem Soc Perkin I 3253-3257 (1999)

23. Vergne C, Bois-Choussy M, Ouazzani J, Beugelmans R, Zhu J. Chemoenzymatic synthesis of enantiomerically pure 4-fluoro-3-nitro and 3-fluoro-4-nitro phenylalanine. Tetrahedron: Asymmetry 8: 391-398 (1997) 